Article

\title{
Severity Multipliers as a Methodology to Explore Potential Effects of Climate Change on Stream Bioassessment Programs
}

\author{
Sonja C. Jähnig 1,2,*, Jonathan D. Tonkin ${ }^{2,3}$, Maria Gies ${ }^{4}$, Sami Domisch ${ }^{1,2}$, Daniel Hering 4 \\ and Peter Haase 2,5 \\ 1 Leibniz-Institute of Freshwater Ecology and Inland Fisheries, Department of Ecosystem Research, \\ Justus-von-Liebig-Str. 7, D-12489 Berlin, Germany; domisch@igb-berlin.de \\ 2 Senckenberg Research Institute and Natural History Museum, Department of River Ecology and \\ Conservation, Clamecystraße 12, D-63571 Gelnhausen; tonkinj@oregonstate.edu (J.D.T.); \\ peter.haase@senckenberg.de (P.H.) \\ 3 Department of Integrative Biology, Oregon State University, 3029 Cordley Hall, 2701 SW Campus Way, \\ Corvallis, OR 97331, USA \\ 4 Department of Aquatic Ecology, Faculty of Biology, University of Duisburg-Essen, Universitätsstrasse 5, \\ D-45141 Essen, Germany; maria.gies@uni-due.de (M.G.); daniel.hering@uni-due.de (D.H.) \\ 5 Department of River and Floodplain Ecology, Faculty of Biology, University of Duisburg-Essen, \\ Universitätsstrasse 5, D-45141 Essen, Germany \\ * Correspondence: sonja.jaehnig@igb-berlin.de; Tel.: +49-6392-4085
}

Academic Editor: Kevin B. Strychar

Received: 22 November 2016; Accepted: 22 February 2017; Published: 3 April 2017

\begin{abstract}
Given the scientific consensus that climate change is impacting biodiversity, estimates of future climate change effects on stream communities and assessments of potential biases are necessary. Here, we propose a simple technique to approximate changes in invertebrate and fish biomonitoring results. Taxa lists for 60 (invertebrate) and 52 (fish) sites were each modified by 10 multipliers as stepwise $5 \%$ or $10 \%$ changes in abundances to simulate potential climate-change severity, reflecting increasing climate change effects. These 10 multipliers were based on the stream zonation preference for invertebrates and the Fish Region Index (FRI) values for fish, both reflecting the longitudinal gradient present in river ecosystems. The original and modified taxa lists were analyzed using the standard assessment software for the particular group, followed by analysis of key biomonitoring metrics. For invertebrates, our simulations affected small good quality streams more often negatively while large poor mountain streams showed a tendency to improve. Forty percent of the invertebrate data sites showed a change in the final ecological assessment class when using the multipliers, with the poor quality sites changing more often. For fish, metric changes were variable, but the FRI ratio showed mostly positive responses, i.e., a shift in FRI towards downstream communities. The results are discussed as an example that facilitates the interpretation of potential climate-change effects with varying severity. Further, we discuss the simplified approach and implications for assessment from climate change induced range shifts.
\end{abstract}

Keywords: benthic invertebrates; climate change; stream zonation; fish; fish regions; water framework directive (WFD)

\section{Introduction}

River ecosystems will most likely be altered by climate change. The modification of temperature and precipitation regimes have the potential to have detrimental (or beneficial) effects and cause synergistic or antagonistic effects on species and communities [1]. Expected changes vary between 
cold, temperate and warm ecoregions, and could affect species due to changes in, among others, temperature, flow patterns, and nutrient concentrations [2-5]. However, estimates of effects from such changes on stream bioassessment results are rare. This calls for a judgment on the possible modifications of communities due to climate change, as well as potential biases on assessment metrics.

The European Water Framework Directive (WFD) requires the assessment of the ecological status of surface waters as a central management tool for European water bodies. Its results guide spatial and temporal prioritization of management actions. For rivers and streams, assessment is currently carried out based on biological, physico-chemical and hydromorphological quality elements for assigned water bodies of certain stream types. For the biological component, four groups of organisms are widely used: phytoplankton, macrophytes, benthic invertebrates, and fish. Metrics reflecting the composition of monitored communities are compared to metrics established on communities in reference condition for a given stream type. A multimetric approach yields the ecological quality class (EQC) and together with the other quality elements an overall result is produced. The ecological status is determined by the deviations of the river stretch from the reference condition as defined by the WFD and classified into five categories: high, good, moderate, poor and bad status. The overall goal within the WFD is for all European freshwater bodies to reach the "good ecological status", originally by 2015 (extended to 2022). In 2009, $43 \%$ of European surface water bodies were classified as in good or high ecological status [6], hence not requiring any action. However, as of 2015, in Germany, for instance, only 8.2\% of all rivers were in good or very good condition, opposed to more than $90 \%$ of rivers classified as moderate, poor or bad status and hence requiring action [7].

Estimating how climate change-induced changes in riverine communities lead to shifts in EQCs values with respect to the WFD is a required step in implementing, adjusting and understanding the outcome of such biomonitoring efforts. If community shifts based on temperature changes alone can alter EQCs, then the present-day status thresholds may no longer be representative in the future. For instance, regardless of present-day conditions, "high" EQC may no longer be achievable. Thus, we need to explore how simple changes in species range shifts that occur through temperature alone may impact the outcome of WFD-dependent biomonitoring metrics.

Research on climate change effects incorporates a wide variety of methods such as field studies [8], lab experiments, and modeling. A number of studies focus on effects on either single species (e.g., $[9,10])$ or communities (e.g., [11]), lacking the step towards the interpretation of these changes in community metrics and associated assessment results. There are few studies on changes in assessment results related to climate change, and few available analyses of long-term data sets [11-13]. All mentioned approaches have their methodological challenges. For instance, range-wide field studies and monitoring are time and cost intensive and laboratory studies lack the ability to scale up the results to natural communities. Moreover, models may be too simplified and the typical presence/absence (or probability of presence) based modeling outputs are often of little use in assessment systems, which require species abundances or abundance classes.

Reflecting changes in abundances, and therefore allowing utility in ecological assessment, we developed and tested a hands-on approach to assess potential climate change effects on WFD-compliant assessment results. An ideal basis for such an analysis requires a suitable empirical database describing hydro-climatic preferences of single species, which could be directly translated into possible climate-change effects. As data that link species directly to their preferred hydro-climatic conditions were not available, we based our approach on the longitudinal structure of rivers reflecting a temperature gradient from cooler small mountain streams to warm lowland large streams [14]. Illies [15] defined distinct stream zones along rivers characterized by their communities, but reflecting a regionally different faunal configuration. These zones are linked to fish faunistic zones including key species like trout, grayling, barbel and bream (Table 1), or through distributional preferences for benthic invertebrates [16] (Table 2). We used these stream zonation preferences to define scenarios of abundance changes in invertebrate and fish communities. For fish, the Fish Region Index (FRI, or Fish Zone Index) describes each fish species' preferred niche along the longitudinal upstream-downstream 
gradient [17] (Table 1). These ecological traits have been shown to mirror changes in fish communities due to climate change through a change in fish regions [17-19] and are also suggested in invertebrate communities [4,5,20]. Pletterbauer et al. [17] showed mean increases of the Fish Zone Index between 0.25 and 0.41 up to the 2080s and maximum values of 0.92 and 1.18 under three climate change scenarios as developed by the Intergovernmental Panel on Climate Change (IPCC). Floury et al. [11] showed a disappearance or decrease in invertebrate taxa typical from fast running, cold waters and appearance and increase of taxa typical from slow flowing or standing waters and warmer temperatures; that is, a shift towards a generalist and pollution tolerant assemblage after a 30-year time period including almost $1{ }^{\circ} \mathrm{C}$ warming. Domisch et al. [21] used European wide species distributions models and showed a potential decrease in headwater taxa under future climates when considering the presence of species.

Table 1. Limnological stream zones according to Illies [15], comprising of the common fish zone, dominant species, related summer temperatures and amplitudes, and respective Fish Region Index (FRI). The FRI is assigned to each fish species, determining the general rule for abundance changes, here exemplified for four dominant species. Headwater/generalist and river taxa were identified according to each species' assigned Fish Region Index (FRI) in most relevant stream zones (grey shadow). Estuary taxa (FRI > 7) were not further considered. See Table 3 for the abundance changes across the 10 multipliers.

\begin{tabular}{|c|c|c|c|c|c|c|c|c|}
\hline Zone & Eu-Crenal & Hypo-Crenal & Epi-Rhithral & Meta-Rhithral & Hypo-Rhithral & Epi-Potamal & Meta-Potamal & Hypo-Potamal \\
\hline Fish zone & & & \multicolumn{2}{|c|}{ Trout zone } & $\begin{array}{l}\text { Grayling } \\
\text { zone }\end{array}$ & $\begin{array}{l}\text { Barbel } \\
\text { zone }\end{array}$ & Bream zone & \\
\hline Dominant species & & & \multicolumn{2}{|c|}{ Salmo trutta } & $\begin{array}{l}\text { Thymallus } \\
\text { thymallus }\end{array}$ & $\begin{array}{l}\text { Barbus } \\
\text { barbus }\end{array}$ & $\begin{array}{l}\text { Abramis } \\
\text { brama }\end{array}$ & \\
\hline Summer temp. ${ }^{\circ} \mathrm{C}$ & & & $<10$ & $<10$ & $<15$ & $>15$ & $\sim 20$ & \\
\hline Amplitude $<{ }^{\circ} \mathrm{C}$ & 2 & 5 & 9 & 13 & 18 & 20 & $>20$ & \\
\hline Fish Region Index (FRI) & & & 3 & 4 & 5 & 6 & 7 & 8 \\
\hline Headwater taxa & & & \multicolumn{3}{|c|}{$\begin{array}{l}\text { FRI } \leq 5.0: \text { Abundance decrease, e.g., } \\
\text { Salvelinus fontinalis, FRI }=3.5\end{array}$} & & & \\
\hline River taxa & & & & \multicolumn{4}{|c|}{$\begin{array}{c}5.0<\text { FRI } \leq 7.0: \text { Abundance increase, e.g., } \\
\text { Barbus barbus, FRI }=6.08\end{array}$} & \\
\hline Estuary taxa & & & & & & & \multicolumn{2}{|c|}{$\begin{array}{c}\text { FRI }>7.0 \text { no change, e.g., } \\
\text { Gasterosteus aculeatus, FRI }=7.17\end{array}$} \\
\hline
\end{tabular}

Table 2. Limnological stream zones according to Illies [15] with the stream zonation preference of invertebrates has been coded as a 10 point distribution for the stream zones, available at http:/ / www.freshwaterecology.info [16]. The sum in each row is 10, the higher the number the higher the preference of the taxon for the respective stream zone. Headwater/generalist and river taxa were identified according to sums of these preference points in most relevant stream zones (grey shadow), determining the general rule for abundance changes. An example species for each group is given and the relevant stream zones for classification are marked grey. Ten multipliers for abundance changes are summarized in Table 3. Note that a separation of generalist and river taxa was not necessary for the current analysis, but is presented here as it may be useful for future studies that would like to apply differing multipliers to each group.

\begin{tabular}{|c|c|c|}
\hline Zone & Eu-Crenal Hypo-Crenal Epi-Rhithral Meta-Rhithral Hypo-Rhithral Epi-Potamal & Meta-Potamal Hypo-Potamal \\
\hline Headwater taxa & $\begin{array}{c}\sum_{\text {preferences }}=8-10: \\
\text { Abundance decrease }\end{array}$ & \\
\hline Generalist taxa & $\begin{array}{c}\sum_{\text {preferences }}=8-10 \text { AND } \\
\text { classification required in all } 5 \text { zones *: } \\
\text { Abundance increase }\end{array}$ & \\
\hline River taxa & & $\begin{array}{c}\sum_{\text {preferences }}=8-10: \\
\text { Abundance increase }\end{array}$ \\
\hline
\end{tabular}


Table 2. Cont.

\begin{tabular}{|c|c|c|c|c|c|c|c|c|}
\hline Zone & Eu-Crenal & Hypo-Crenal & Epi-Rhithral & Meta-Rhithral & Hypo-Rhithral & Epi-Potamal & Meta-Potamal & Hypo-Potamal \\
\hline \multicolumn{9}{|l|}{ Examples } \\
\hline $\begin{array}{l}\text { Odontocerum albicorne } \\
\text { (headwater) }\end{array}$ & 0 & 2 & 7 & 1 & 0 & 0 & 0 & 0 \\
\hline Baetis rhodani (generalist) & 0 & 1 & 2 & 3 & 2 & 1 & 1 & 0 \\
\hline $\begin{array}{l}\text { Aphelocheirus aestivalis } \\
\text { (river) }\end{array}$ & 0 & 0 & 0 & 0 & 2 & 8 & 0 & 0 \\
\hline $\begin{array}{c}\text { Polycentropus } \\
\text { flavomaculatus (no change) }\end{array}$ & 0 & 0 & 0 & 2 & 2 & 2 & 2 & 2 \\
\hline
\end{tabular}

Notes: * "classification required in all 5 zones" means that a preference value should be given in all five stream zones marked grey; if the sum is 8-10 for only three or four of the five zones, the taxon is not grouped as "generalist". For example, Polycentropus flavomaculatus does not match the criterion that the sum of preferences should be 8-10 and a value should be given in either of the stream zones, as abundances would hence not change.

We developed a simple ruleset that allowed us to show how alterations in community composition might impact the ecological assessment results. Alterations were based on assumptions of changes in community composition related to stream zonation preferences of invertebrates and fish, which are broadly linked to climate change. We then (1) compare potential changes in invertebrate and fish communities through metrics and overall assessment results; and (2) analyze whether any changes in community composition would be contingent on the stream type (based on stream size and ecoregion) and for the original ecological condition of the site (comparing sites of either good or poor/bad status).

\section{Materials and Methods}

\subsection{Fish and Benthic Invertebrate Data}

For our fish and benthic invertebrate data, we aimed for datasets comprising 10 sites of high or good and 10 sites of poor or bad status each from three stream types (hereafter "original data"): small mountain streams, large mountain streams, and small lowland streams (size follows the official classification of the German river assessment, with small and large having a catchment size of $10-100 \mathrm{~km}^{2}$ and $100-1000 \mathrm{~km}^{2}$, respectively). This yielded 60 sites for invertebrates and 52 sites for fish (less sites for fish due to the lack of "good" sites in large mountain and small lowland streams). Species abundance data for each site (i.e., a taxa list) were provided by the local water authorities.

\subsection{Multipliers Reflecting Climate Change Effects}

Our approach can be seen as an extension of the taxonomic model presented by Hamilton et al. [12], who removed all cold-dwelling taxa from taxa lists prior to the calculation of assessment results. Expanding on this approach, we defined multipliers for baseline abundances to apply abundance changes (increase or decrease) of individual taxa depending on their specific stream zonation preference (Figure 1, Tables 1 and 2).

Taxa that we assumed to react either negatively or positively to climate change were modified by 10 multipliers (Table 3). Each multiplier reflects an increasing scenario of severity of climate-change net-effect in community composition (hence, named S1 to S10), where, for instance, scenario S2 has a more severe impact on the community than scenario S1. Hence, these scenarios do not reflect direct temperature or precipitation changes as given by the representative concentration pathways (RCPs) of greenhouse gases [22] but the overall potential positive or detrimental effect on communities. They thus represent a simplified ruleset of stream-specific alterations due to climate change that are linked to the longitudinal structure of rivers, reflecting a temperature gradient. We chose this proximate approach as for invertebrates direct temperature preference was available for only 115 taxa [16] of the German operational taxa list (889 taxa, February 2010, [23]), while longitudinal preference as an ecological trait closely related to temperature was available for 560 taxa. Similar for fish, no temperature preference data were available but each fish species is assigned to a certain fish region characterized by certain temperature patterns (Table 1). 


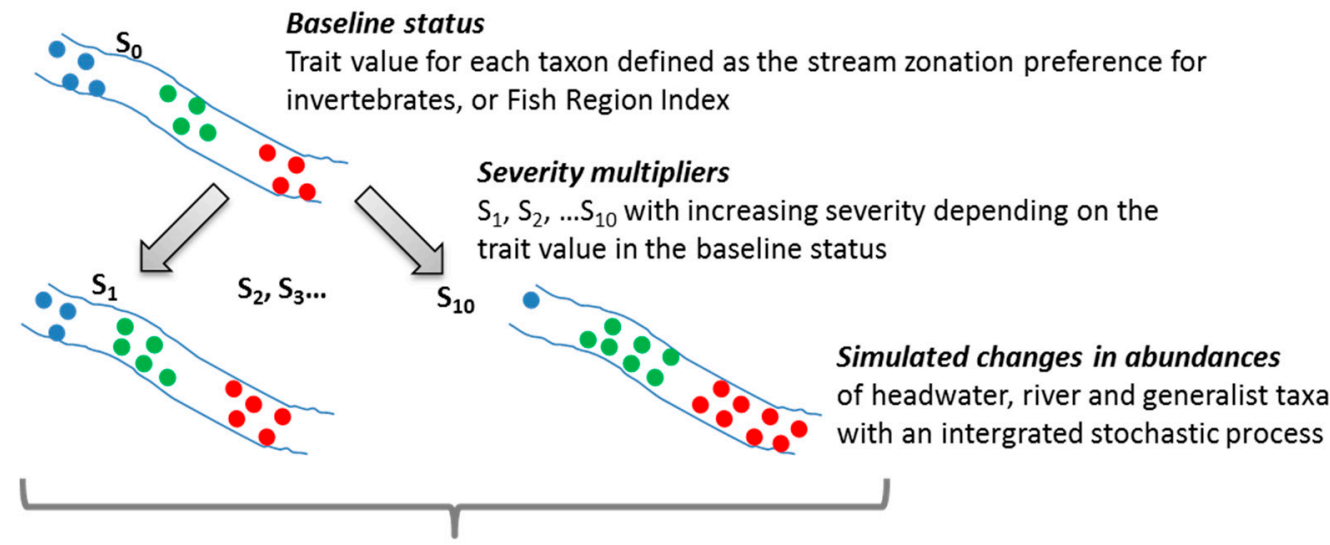

- ASTERICS and FIBS assessment scores for each taxa list

- Relative changes in community metrics

- Stream types and different baseline ecological conditions analysed separately

Figure 1. Schematic procedure of the ruleset application to assess potential climate change effects on assessment results. Colored dots represent three different taxa (blue = headwater taxon, green = river taxon, red = generalist) at a baseline S0, and after applying severity multipliers for S1 to S10 that simulate changing abundances of individual taxa (for details, please see main text and Tables 1-3, which describe the stream and fish zones assignments for each species, respectively, and the multipliers applied to these). These simulated abundances are then used to calculate new ASTERICS and FIBS assessment scores, potential changes in community metrics within different stream types.

For invertebrates, stream zonation preference is coded based on a 10-point distribution for the respective stream zones (see Table 2). Headwater, river and generalist taxa were identified according to sums of these preference points from the freshwaterecology.info database [16] (Supplementary Table S3). We defined ten $10 \%$ increments to apply a decrease or increase in abundance (Table 3). We translated results from modeling studies from Domisch et al. $[4,21]$ where expanding species range changes occurred for species with higher mean annual temperature preferences in general (negative changes for low temperature preferring taxa) and expanding range changes for species which were attributed as "lowland river species" in particular ([21]; following roughly similar grouping rules). Similar to Domisch et al. [21], we argue that generalist taxa are best buffered against climate change impacts (e.g., [24], and references therein arguing for their dispersal capacities). Accordingly, we assumed abundance decrease for headwater taxa given their cold water preference and potential warming effects due to climate change and accordingly an abundance increase for river and generalist taxa. For invertebrates, the increase was distributed among the two latter groups (river and generalist taxa), hence we divided each increment, yielding $5 \%$ increments. For fish, we defined an increase or decrease of abundance in even increments of $10 \%$ depending on the FRI values of each taxon (Table 3 , Supplementary Table S4). We followed a similar approach as for invertebrates, assuming abundance decrease for headwater associated taxa (FRI $\leq 5.0)$ and an increase for river taxa $(5.0<$ FRI $\leq 7.0)$ and no change to taxa with FRI $>7.0$ which are mainly associated to estuaries not considered in this study. For both invertebrates and fish, each single species is assigned separately to a stream zonation and not from the communities they might occur in, avoiding circularity in assignment (i.e., the method was applied on a species-by-species, not community, basis).

We assumed a Poisson distribution of abundance of each taxon to realize these abundance changes, and to incorporate and simulate stochasticity within the approach (see Appendix "Rcode" for R-script). The Poisson distribution predicts the degree of spread around a known average rate of occurrence. The number of observed occurrences fluctuates around its mean $\lambda$ with a standard deviation of $\sqrt{\lambda}$. The Poisson distribution is thus estimated from the original abundance value (and described by $\lambda$ ). The Poisson distribution is estimated from increasing or decreasing the original abundance value by 
the multiplier value ("scenario") from Tables 2 and 3 and drawing a new abundance value from this new distribution.

Table 3. Multipliers to baseline abundances to realize abundance changes for benthic invertebrates and fish species according to stream zonation preferences and FRI, respectively as shown in Tables 1 and 2. $\mathrm{n} / \mathrm{a}$ = taxa not classified for stream zonation preference, e.g., coarse taxonomic units or do not match criteria in Table 1. S1 to S10 reflect an increasing severity of climate-change effects on community composition.

\begin{tabular}{lccccccccccc}
\hline & & S1 & S2 & S3 & S4 & S5 & S6 & S7 & S8 & S9 & S10 \\
\hline Invertebrates & & & & & & & & & & & \\
\hline Headwater taxa & $<$ & 0.9 & 0.8 & 0.7 & 0.6 & 0.5 & 0.4 & 0.3 & 0.2 & 0.1 & 0.0 \\
Generalist taxa & $>$ & 1.05 & 1.1 & 1.15 & 1.2 & 1.25 & 1.3 & 1.35 & 1.4 & 1.45 & 1.5 \\
$\quad$ River taxa & $>$ & 1.05 & 1.1 & 1.15 & 1.2 & 1.25 & 1.3 & 1.35 & 1.4 & 1.45 & 1.5 \\
n/a & $/$ & 1.0 & 1.0 & 1.0 & 1.0 & 1.0 & 1.0 & 1.0 & 1.0 & 1.0 & 1.0 \\
\hline Fish & & & & & & & & & & & \\
\hline FRI $\leq 5.0$ & $<$ & 0.9 & 0.8 & 0.7 & 0.6 & 0.5 & 0.4 & 0.3 & 0.2 & 0.1 & 0.0 \\
5.0 $<$ FRI $\leq 7.0$ & $>$ & 1.1 & 1.2 & 1.3 & 1.4 & 1.5 & 1.6 & 1.7 & 1.8 & 1.9 & 2 \\
FRI $>$ 7.0 & $/$ & 1.0 & 1.0 & 1.0 & 1.0 & 1.0 & 1.0 & 1.0 & 1.0 & 1.0 & 1.0 \\
\hline
\end{tabular}

For each original taxa list (named S0), 10 scenario-taxa lists were calculated (S1-S10), forcing an increasing effect. Each taxa list was analyzed using the standard assessment software for invertebrates (ASTERICS, http://www.fliessgewaesserbewertung.de/en/download/berechnung/, 60 original, 600 scenario lists,) and fish (FIBS, http://www.lazbw.de/pb/,Lde/Startseite/Fischereiforschungsstelle/ FIBS, 52 original, 520 scenario lists).

We highlight that this approach provides a test of how communities might be affected by climate warming given a ruleset of possible alterations in community structure. The results can be therefore seen as an approximation, and how such potential alterations may be transposed into assessment results. The attached R-script and example data sheet serves as a template to test the method on own data.

\subsection{Metrics and Assessment Results}

The standard assessment software for both groups (see above) automatically provides metrics for each taxa list analyzed. These metrics were derived from the original and scenario assessment results. For each organism group, four general key metrics were selected, including taxonomic richness and abundance for both. For invertebrates, the share of mayflies, stoneflies, caddisflies (Ephemeroptera, Plecoptera, and Trichoptera (EPT\%)) and general degradation were additionally analyzed; general degradation is a core module in the German assessment system reflecting morphological degradation and catchment land use [25]. For fish, FRI (introduced above) and Ecological Quality Ratio (EQR) were analyzed. EQR reflects the final ecological condition according to the fish community and may take values between 0 (bad quality) and 1 (reference conditions). Results are shown for the original and aggregated values as mean relative changes for 10 scenarios where streams within a given stream type are treated as replicates. To test which scenarios differ significantly from 1 (i.e., no change in ratio from original to climate change scenario), we ran one-sample $z$-tests, specifying 1 as the $\mu$ value. In the $z$-test, $\mu$ is a single number representing the value of the mean specified by the null hypothesis. We used the $z$-test in the package BSDA, version 1.01 in $\mathrm{R}$ version 3.2.2 [26,27].

For invertebrates, we further calculated the Ecological quality class (EQC) value (5 classes) and analyzed whether shifts in EQCs could be detected. 


\section{Results}

Given our multipliers, 51\% of the invertebrate taxa remained unchanged in their abundance (under all scenarios), only $6 \%$ experienced a decrease and $43 \%$ experienced an increase by the multiplier runs. For fish, $12 \%$ remained unchanged, $20 \%$ of taxa experienced abundance reduction, and $68 \%$ experienced an increase.

\subsection{Invertebrates}

Taxa numbers were highest in small mountain streams and lowest in small lowland streams, with poor quality sites having lower taxa numbers than good quality sites (Supplementary Figure S1A). Taxa numbers for invertebrates decreased in all stream types with the multipliers, and relative changes (i.e., value $<1$ ) were significant ( $p \leq 0.05$ ) with few exceptions (Figure 2A, Supplementary Table S1 for all z-test-results). Small good quality streams (mountain and lowland) showed an overall decrease of taxa numbers when multipliers increased from S1 to S10. Poor quality streams showed less decrease with more severe multipliers and fluctuating ratios. Relatively small changes were observed for large mountain streams, with those of good quality showing the least changes overall.

Abundances were highest in large mountain streams and lowest in small lowland streams, but poor quality lowland streams had higher invertebrate numbers than good quality streams (opposed to other stream types, Supplementary Figure S1B). Abundances consistently increased in all stream types across the multipliers with S10 triggering the strongest changes (Figure 2B). Largest changes were observed in small good quality lowland streams and smallest increases in large mountain streams irrespective of quality.

EPT shares were highest in small mountain streams and lowest in small lowland streams, with poor quality sites having lower EPT share than good quality sites (Supplementary Figure S1C). Relative changes were small compared to taxa numbers or abundance changes and significant only at higher multiplier scenarios for small good quality mountain streams (decrease) and increasing ratio for poor large mountains streams. In other stream types, the changes were variable (Figure 2C).

The general degradation scores were clearly distinct for good and poor quality sites within the stream types (Supplementary Figure S1D). The relative changes were again inconsistent across multipliers with considerable fluctuations (Figure 2D). Small good quality mountain streams showed small but significant negative ratios with increasing multipliers, while large poor quality mountain streams showed positive ratios (i.e., improving metric values), suggesting an improved assessment result.

Changes in EQC were either one class down or up, or zero (Figure 3). Deterioration occurred only in the sites of originally poor status. Overall changes in EQC were observed in 24 of the 60 sites and, of these, for nine sites the change went either from good to medium or medium to good. Large good mountain streams showed no changes in EQC, while poor mountain streams showed deterioration by one EQC in the higher multiplier scenarios. All other stream types showed improvement of one EQC, but already with lower multipliers. 


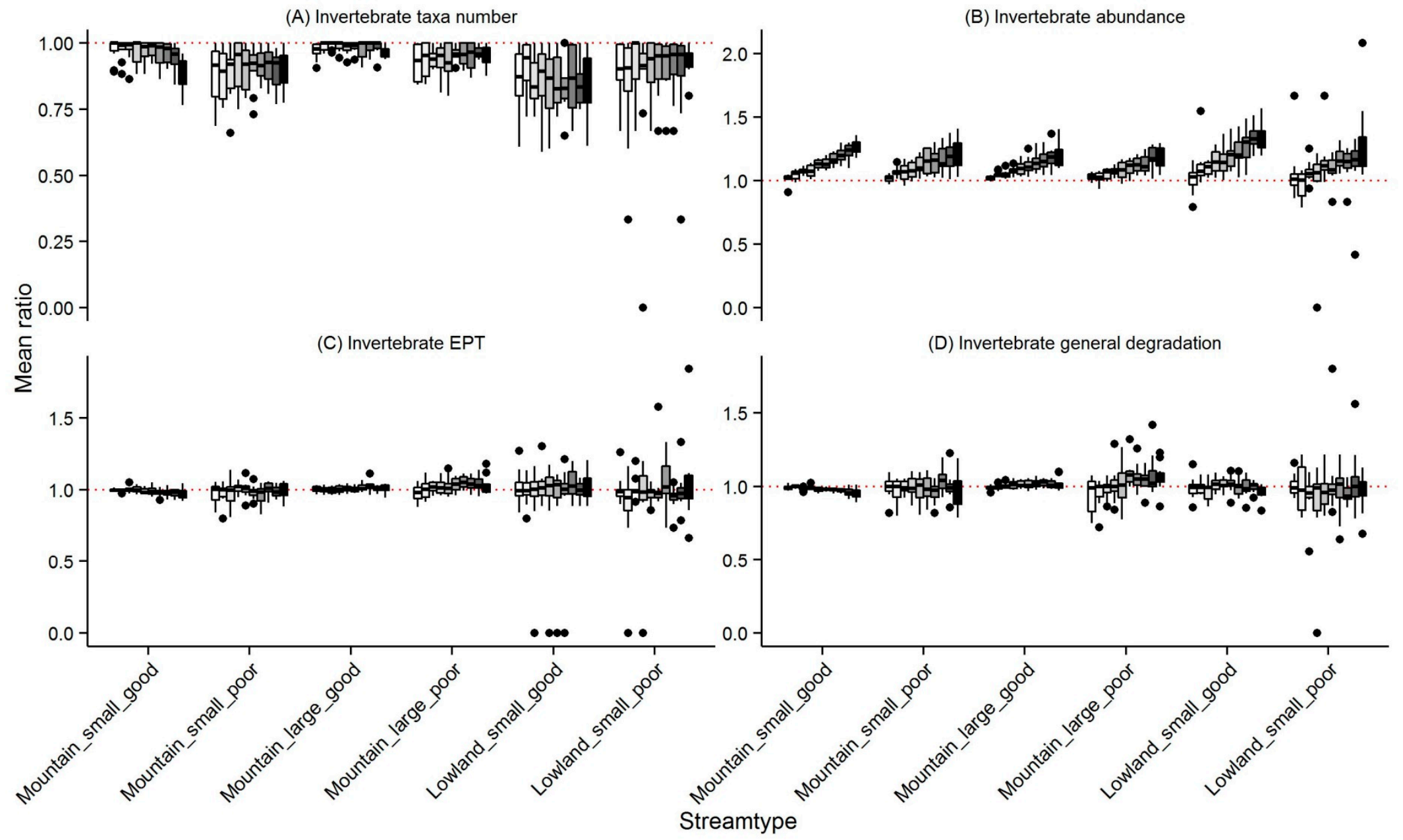

Figure 2. (A-D) Relative mean changes for the 10 multiplier scenarios (from white $=\mathrm{S} 1$ to black $=\mathrm{S} 10$ ) in key metrics for invertebrate communities (taxa number, abundance, proportion EPT, and general degradation score, respectively); points resemble outliers to boxplots. 


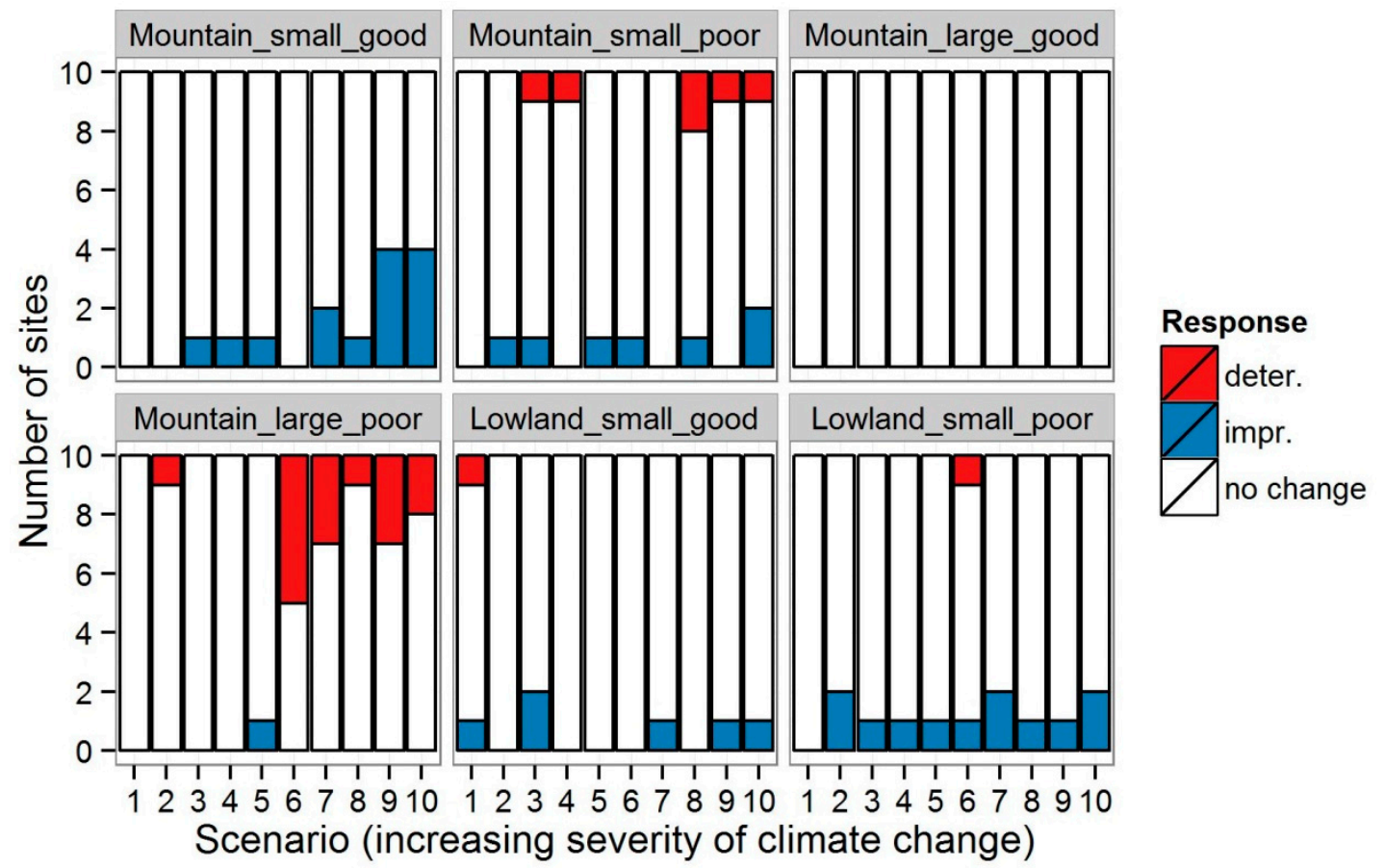

Figure 3. Number of sites changing in ecological quality classes (EQC, invertebrate data) per scenario (on y-axis) for different stream types. Changes were either one class down ("deter." = deterioration) or up ("impr." = improvement), or zero ("no change"), where no larger changes in EQC occurred.

\subsection{Fish}

Fish taxa numbers varied considerably between stream types and quality classes, but small good quality mountain streams together with small poor quality lowland streams had lowest taxa numbers (Supplementary Figure S2A). Taxa numbers (naturally, due to the method) only decreased along the scenarios, with S10 causing the largest relative changes and highest variability in changes (Figure 4A, Supplementary Table S2 for all $z$-test-results).

Individual numbers were lowest in small mountain streams but varied in other stream types (Supplementary Figure S2B). Ratios changed consistently with the stream types (i.e., either significantly increased or decreased with increasing multipliers; Figure 4B), and the variability of ratios increased with higher scenarios. Small good quality lowland and mountain streams were the two stream types where individual numbers decreased.

The FRI was lowest for small good quality mountain streams and highest for small poor quality lowland streams; large mountain streams included sites with FRI values from 3.9 to 6.6 (Supplementary Figure S2C). FRI values showed significant increase with increasing scenarios for small poor mountain, large good mountain and small good lowland streams (Figure 4C) or virtually did not change for the others. Generally, variability was higher for more severe scenarios.

EQR were distinctly higher for good than for poor quality sites within the stream types (Supplementary Figure S2D). Small poor quality mountain streams showed increasingly negative ratios with increasing multipliers (Figure $4 \mathrm{D}$ ), while other changes were not significant. For most stream types, variability was higher for more severe scenarios. 


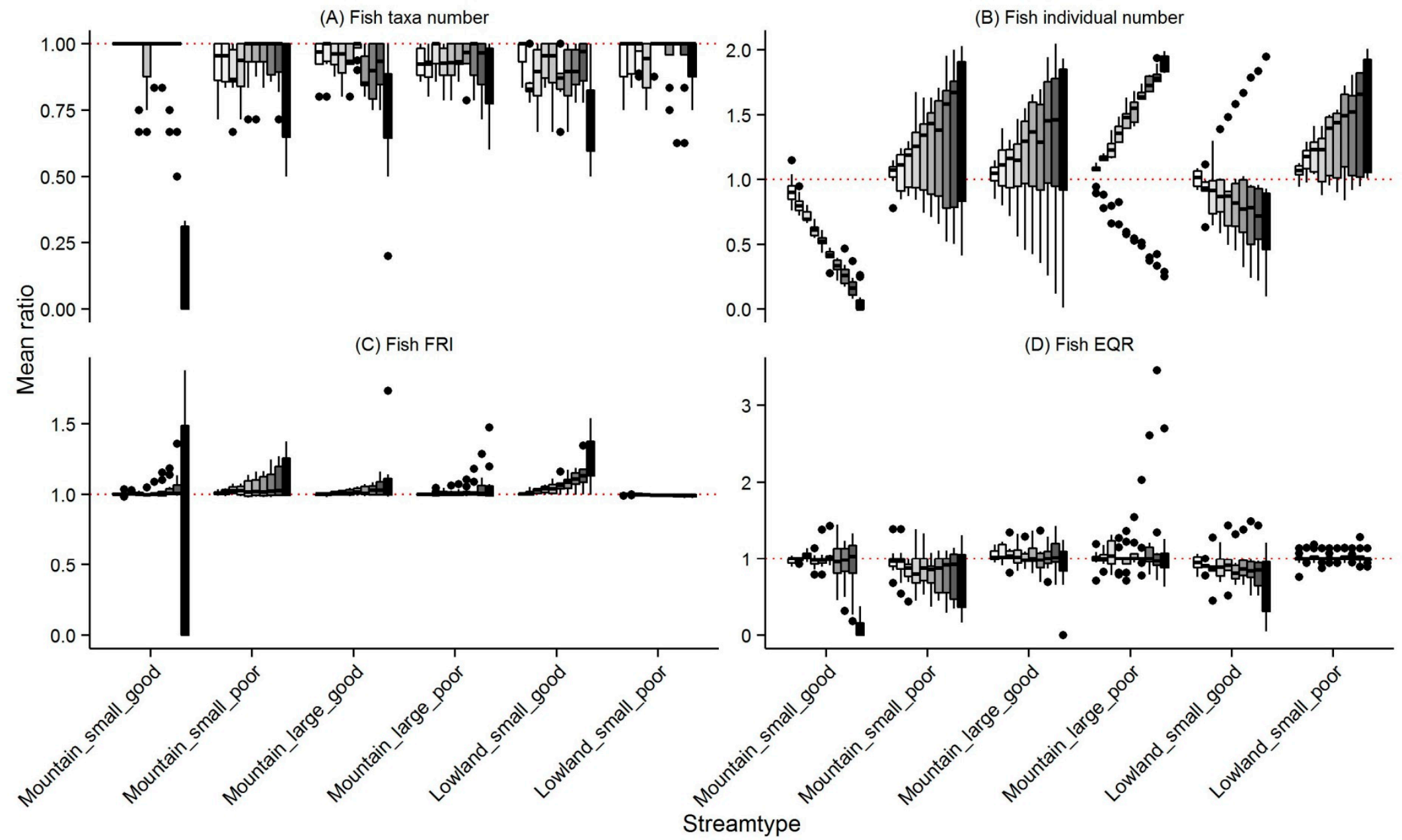

Figure 4. (A-D) Relative mean changes for 10 multiplier scenarios (from white = S1 to black = S10) in key metrics for fish (taxa number, individual number, FRI, general and EQR score, respectively); points resemble outliers to boxplots. 


\section{Discussion}

\subsection{Changes in Community Metrics}

For invertebrates, our results showed a decrease in taxa number with increasing multipliers in all stream types with small good quality streams showing a stronger decrease. Abundances increased in all stream types across multipliers, again smaller streams experienced larger changes. EPT changes were rather small and significantly smaller only for small good quality mountain streams at higher multipliers, while increasing in large poor mountain streams. This in turn influenced the results of general degradation scores in these stream types (small but significantly decreasing in small good and increasing in large poor mountain streams at some of the higher multipliers). These changes can partially be attributed to the methodology used and severity multipliers designed (see below for in-depth discussion). In a 20-year study in Mediterranean streams, richness was found to be a robust metric together with EPT\% [13], reflecting that in reality sites experience losses and gains of taxa. Our data are limited to decreasing richness only, as we only represented taxa losses, not gains.

Our approach allowed an estimation of changes in assessment results for invertebrate samples, rarely seen until now, but suggested, e.g., by Wilby et al. [28]. Forty percent of the invertebrate data sites (across all stream types/quality classes) showed a change in EQC when using the multipliers, with the poor quality sites changing more often. Site classification changes were also demonstrated in Hamilton et al. [12] who found that losing cold-dwelling and gaining warm-dwelling taxa would likely mean a higher Hilsenhoff's biotic index (HBI, overall lower site-condition classifications) in three states in the US.

For fish taxa, numbers also decreased with increasing multipliers. Individual numbers in small good quality lowland and mountain streams decreased as well, while in other stream types, numbers increased but showed a large variability. The FRI ratio changes demonstrated mostly positive responses (i.e., a shift in FRI towards downstream communities). For the EQR only small poor quality mountain streams showed increasingly negative ratios with increasing multipliers. The FRI indicating a more downstream influenced community is in line with other studies on climate change effects on fish $[19,29,30]$. The actual differences in FRI of the communities range from a negligible -0.03 in poor small lowland and good small mountain streams, up to 0.37 in small good lowland streams; they are thus on average lower than the zonal changes modelled by Pletterbauer et al. [19] for three future emission scenarios (A1b, A2, and B1). We did not further analyze EQR in fish assessment results due to missing key influential components for fish assessments, particularly size and age structure, which have been shown to change due to climate change [30].

Climate change is likely to have a major influence on riverine biota, including by altering winter temperatures and affecting fish spawning, or summer temperatures causing physiological stress [31]. These and many other influences will likely eventually alter reference conditions [32]. Thus, it is important to understand these changes in relation to other anthropogenically driven changes for which biomonitoring metrics were designed to monitor. The results highlight the need for further testing of the vulnerability of bioassessment metrics to various aspects of global change and the potential for adopting metrics related specifically to climate change (e.g., $[13,33,34])$.

\subsection{Directions for Future Analyses}

Our approach is based on a number of simplifications, but should be understood as an exploratory approach, and, by necessity, utilizes a simplistic approach to address a complex problem. We highlight that the multiplier scenarios S1-S10 used here are not linked to actual climate scenarios, but to the longitudinal structure of rivers, reflecting a temperature gradient from cooler small mountain streams to warm lowland large streams. Further, it assumes linear responses, a single stressor (temperature) and only allows for taxon decreases (not immigration from downstream). However, a linear response (increasing from multiplier S1 to multiplier S10) is not the only possible response type, as non-linear responses and tipping points are often present [35]. If known, these 
response types could be adopted when defining the multipliers S1-S10 in a non-linear manner. Another methodological improvement would be to consider limitations in the carrying capacity in a river section and respective sample, as especially for the river and generalist taxa, abundances may become unrealistically high. Additionally, other stressors are important in freshwater ecosystems [36] and antagonistic or synergistic effects are likely at play [37]. Temperature changes themselves can be variable in stream networks due to various causes with different ecological effects, such as climate change sensu strictu, but also from land use change (e.g., deforestation) or hydrological changes (e.g., water abstractions) [38]. The different multipliers for headwater, river and generalist taxa consider that cold and warm-dwelling taxa might respond differently to climate change [32,39]. Future applications could consider other scenarios, such as acknowledging that river specialist taxa might also decline or consider a refined FRI-based multiplier ruleset, e.g., including generalist species, too. Further, we assume only a decrease of headwater species but other ecological traits could render taxa sensitive to climate change, too (e.g., life cycle traits associated to flow [40,41]). In principal, the ruleset-methodology can be applied to other ecological parameters or species traits to compare the potential effects of any changes that act on different functional groups of a community. In addition, we did not consider adaptive potential of species or species gains. For the latter, we had no information on surrounding species pools for each site, which are a source of primary colonizers in restoration projects [42,43]. Arguably, generalist taxa and/or invasive species would be most likely to immigrate [44,45], in turn reducing ecological quality. Potential source populations could be considered for species gains, e.g., depending on their dispersal capacity [46], or a possible distance decay function considering distance of the source population and/or time. In contrast, an ongoing ecological recovery of streams in Europe since industrial times has been reported [47], making it difficult to use today as a starting point for "negative" changes as streams are still recovering positively. Considering only the loss of taxa so far is further aggravated by what could be called the " $\lambda$-problem": if a taxon has an abundance of zero, it will always be zero in the scenarios as well, although there might be a small population from which taxa could survive. In a future application of this approach, this problem could be reduced by adding a small constant to each "zero" to make these taxa "available".

While our approach tried to assume some variability in outcome by calculating replicates, a certain over-modulation is still visible in sites with very low species numbers (e.g., mountain fish communities). Non-significant results in small good mountain and small poor lowland streams for fish can be linked to many sites with only two taxa. Further, non-significant results occurred in the stream types with fewer sites (small good lowland and large good mountain streams).

\subsection{Climate Change Induced Range Shifts and Implications for Assessment}

Climate-change induced shifts in the longitudinal distribution of stream organisms are inevitable but there will be significant variability in this movement. Whether movements upstream in river networks, with elevation, or northwards will be the primary mechanism of dispersal in relation to climate warming is uncertain, but a recent study by Haase et al. [48], indicates that elevation is the key factor for benthic invertebrates. Nevertheless, aspects of connectivity of adjacent catchments will affect the dispersal of organisms in relation to moving temperature niches, including the level of movement within and between catchments. This will likely depend on the dispersal capacity of organisms [49,50]. For poor dispersers that cannot disperse across catchment boundaries (i.e., overland) in headwater streams, the summit-trap effect may play a role [21] (but see Isaak et al. [51]). However, evidence suggests that between-catchment dispersal is common and strong for insects [52]. For fish, the connectivity, river network structure and intrinsic as well as extrinsic (anthropogenic) impacts and migration barriers are essential $[19,53,54]$.

All of these variable elements will influence the outcome of climate warming on stream communities and eventually on biomonitoring metrics. Understanding these dispersal-related influences on future effects of climate change is difficult, particularly given the varied dispersal ability of stream invertebrates (and fish) and the inherent dendritic structure of river networks [55], and the 
dependence of some species on within-network dispersal and some freely dispersing across catchment boundaries. This aligns with a recent call for biomonitoring and bioassessment of freshwaters to consider metacommunity dynamics [56]. Recent evidence suggests that niche control (i.e., species sorting) in rivers is only part of the equation, with dispersal-related influences (e.g., mass effects, and dispersal limitation) playing a major role in structuring stream communities [50]. It is likely that dispersal limitation will play a key role in the outcome of future climate warming and related shifts in community composition, with many weak dispersers potentially not keeping up with climate change.

Our study scans possible effects of community changes which can broadly be related to climate change on river bioassessment results in Germany. The study is based on a national dataset and hence general conclusions beyond the study region should be drawn with care. Despite the methodological constraints we believe that the general procedure gives some indication on the effects on assessment results. The presented ruleset is further an adaptable approach independent of time- and cost-intensive experiments or field studies. Differing to modeling approaches, it has the advantage of producing abundance data, which is required for the assessment programs complying to the WFD.

Our results support water managers in estimating how changes in riverine communities associated to climate change lead to shifts in EQCs values with respect to the WFD. The observed shifts based on assumed temperature changes alone altered EQCs, suggesting further explorations. First, the necessity to follow such a simplified approach urgently calls for observations or enhanced prognoses of temperature changes, precipitation distribution and effects on the flow regime and its subsequent effects on riverine species. An important yet unanswered question is whether the present-day status thresholds will be representative in the future. That is, under climate change, will "high" EQC still be achievable, regardless of present-day conditions? Examining impacts of climate change on reference conditions is thus indispensable, but is best achieved through long term monitoring of sites. Hering et al. [57] suggests a network of reference sites including high status, but also degraded and restored sites, possibly linked to the LTER network [58], which would allow exploring response trajectories and resilience of metrics. Monitoring should also extend to other emerging stressors hitherto not considered in the current European assessment systems like siltation, toxic substances, pathogens, or alien species. Better knowledge of species reactions to changes (in either direction) could be used in a refined version of our ruleset, either by estimating stressor effects of changes to assessment results or as an easy-to-apply tool to test effects of management measures, and how these might potentially affect assessment results. We also argue to keep assessment systems flexible and add metrics, related to climate change based on empirically based temperature preferences of taxa [59]. While such a metric mirrors climate change, other temperature changes would also be represented like backwaters, missing shade, cooling water inflows or discharge changes which lead to changed temperatures.

Supplementary Materials: The following are available online at www.mdpi.com/2073-4441/9/4/188/s1. Table S1. List of $z$-test results for four invertebrate metrics for different stream types; estimated mean ratios and $p$-value indicating a difference from $\mathrm{mu}=1 ; p$ values $\leq 0.05$ are highlighted; $\mathrm{S}$ refers to severity multiplier, Table S2. List of $z$-test results for four fish metrics for different stream types; estimated mean ratios and P-value indicating a difference from $\mathrm{mu}=1 ; p$ values $\leq 0.05$ are highlighted; $\mathrm{S}$ refers to severity multiplier, Table S3. List of invertebrate taxa and their classification into headwater, river, generalist or $\mathrm{n} / \mathrm{a}$-taxa, Table S4. List of fish species in samples analyzed and their Fish Region Index (FRI), Figure S1 (A-D). Values of key metrics for invertebrate communities (taxa number, abundance, proportion EPT, general degradation score) for original and scenario data. Sites are ordered for increasing metric value for each metric, i.e., that point 1 in Figure S1A is not necessarily the same sampling site as point 1 in Figure S1B, Figure S2 (A-D). Changes in values of key metrics for fish communities (taxa number, individuals, FRI, general EQR score) for original and scenario data. Sites are ordered for increasing metric value for each metric, i.e., that point 1 in Figure S2A is not necessarily the same sampling site as point 1 in Figure S2B. Rcode: A ruleset to estimate potential climate-change effects on river and stream assessment results for benthic invertebrates and fish. Example_taxa_list. Example data sheet for the R-code.

Acknowledgments: Data were provided through two national funded projects on climate change effects on the biological quality of rivers and streams, funded by the KLIWA-consortium ("Climate change and consequences for water management") and by the state of Hesse, as well as by Andrea Sundermann, Stefan Stoll and Peter Rolauffs. We are grateful to 30 representatives of southern German water authorities in charge of water management plans and monitoring linking our study to the real-world application and management. In the course of these 
projects, we developed the overall procedure during three workshops with them, deciding which ecological traits might be useful climate-change proxies and the multiplier method. We would like to thank Brooks Ferebee of Goethe University for providing the multiplier scenario R-code and Karan Kakouei for helping with the loop-code for the z-test. Denise Früh is thanked for assisting with the literature search in the KLIWA project. Sonja C. Jähnig acknowledges the funding from the German Federal Ministry of Education and Research (BMBF) for the "GLANCE" project (Global change effects in river ecosystems; 01LN1320A). We thank Alain Maasri and four reviewers for valuable comments on earlier versions of the manuscript.

Author Contributions: Sonja C. Jähnig, Maria Gies, Daniel Hering and Peter Haase conceived and designed the experiments; Sonja C. Jähnig performed the experiments; Sonja C. Jähnig and Jonathan D. Tonkin analyzed the data; Sami Domisch and Daniel Hering contributed reagents/materials/analysis tools; Sonja C. Jähnig wrote the paper; Jonathan D. Tonkin contributed to the discussion; and all authors contributed to drafts of the manuscript.

Conflicts of Interest: The authors declare no conflict of interest. The founding sponsors had no role in the design of the study; in the collection, analyses, or interpretation of data; in the writing of the manuscript, and in the decision to publish the results.

\section{Abbreviations}

The following abbreviations are used in this manuscript:

$\begin{array}{ll}\text { ASTERICS } & \text { AQEM/STAR Ecological River Classification System; the standard assessment software for } \\ \text { BSDA } & \text { several European states based on invertebrates } \\ \text { EPT } & \text { Ephic Statistics and Data Analysis" package in r, version 1.01 } \\ \text { EQC } & \text { Ecological Quality Class } \\ \text { EQR } & \text { Ecological Quality Ratio } \\ \text { FIBS } & \text { Fischbasiertes Bewertungssystem, german for: fish-based assessment system; standard } \\ \text { FRI } & \text { assessment software for fish in Germany } \\ \text { HBI } & \text { Fish Region Index } \\ \text { IPCC } & \text { Hilsenhoff's biotic index } \\ \text { S0 } & \text { Intergovernmental Panel on Climate Change } \\ \text { S1-S10 } & \text { original taxa list } \\ \text { WFD } & \text { 10 multiplier scenarios, where higher numbers indicate an increasing climate change effect }\end{array}$

\section{References}

1. Vörösmarty, C.J.; McIntyre, P.B.; Gessner, M.O.; Dudgeon, D.; Prusevich, A.; Green, P.; Glidden, S.; Bunn, S.E.; Sullivan, C.A.; Liermann, C.R.; et al. Global threats to human water security and river biodiversity. Nature 2010, 467, 555-561. [CrossRef] [PubMed]

2. Reist, J.D.; Wrona, F.J.; Prowse, T.D.; Power, M.; Dempson, J.B.; Beamish, R.J.; King, J.R.; Carmichael, T.J.; Sawatzky, C.D. General effects of climate change on Arctic fishes and fish populations. Ambio 2006, 35, 370-380. [CrossRef]

3. Brown, L.E.; Hannah, D.M.; Milner, A.M. Vulnerability of alpine stream biodiversity to shrinking glaciers and snowpacks. Glob. Chang. Biol. 2007, 13, 958-966. [CrossRef]

4. Domisch, S.; Jähnig, S.C.; Haase, P. Climate-change winners and losers: Stream macroinvertebrates of a submontane region in Central Europe. Freshw. Biol. 2011, 56, 2009-2020. [CrossRef]

5. Bonada, N.; Doledec, S.; Statzner, B. Taxonomic and biological trait differences of stream macroinvertebrate communities between mediterranean and temperate regions: Implications for future climatic scenarios. Glob. Chang. Biol. 2007, 13, 1658-1671. [CrossRef]

6. European Commission. Report from the Commission to the European Parliament and the Council on the Implementation of the Water Framework Directive (2000/60/EC) River Basin Management Plans; European Commission: Brussels, Belgium, 2012.

7. Arle, J.; Mohaupt, V.; Kirst, I. Monitoring of Surface Waters in Germany under the Water Framework Directive-A Review of Approaches, Methods and Results. Water 2016, 8, 217. [CrossRef] 
8. Woodward, G.; Perkins, D.M.; Brown, L.E. Climate change and freshwater ecosystems: Impacts across multiple levels of organization. Philos. Trans. R. Soc. Lond. B Biol. Sci. 2010, 365, 2093-2106. [CrossRef] [PubMed]

9. Haidekker, A.; Hering, D. Relationship between benthic insects (Ephemeroptera, Plecoptera, Coleoptera, Trichoptera) and temperature in small and medium-sized streams in Germany: A multivariate study. Aquat. Ecol. 2008, 42, 463-481. [CrossRef]

10. Oliva-Paterna, F.J.; Torralva, M.; Fernández-Delgado, C. Threatened Fishes of the World: Aphanius iberus (Cuvier \& Valenciennes, 1846) (Cyprinodontidae). Environ. Biol. Fish. 2006, 75, 307-309.

11. Floury, M.; Usseglio-Polatera, P.; Ferreol, M.; Delattre, C.; Souchon, Y. Global climate change in large European rivers: Long-term effects on macroinvertebrate communities and potential local confounding factors. Glob. Chang. Biol. 2013, 19, 1085-1099. [CrossRef] [PubMed]

12. Hamilton, A.T.; Stamp, J.D.; Bierwagen, B.G. Vulnerability of biological metrics and multimetric indices to effects of climate change. J. N. Am. Benthol. Soc. 2010, 29, 1379-1396. [CrossRef]

13. Lawrence, J.E.; Lunde, K.B.; Mazor, R.D.; Bêche, L.A.; McElravy, E.P.; Resh, V.H. Long-term macroinvertebrate responses to climate change: Implications for biological assessment in mediterranean-climate streams. J. N. Am. Benthol. Soc. 2010, 29, 1424-1440. [CrossRef]

14. Allan, J.D.; Castillo, M.M. Stream Ecology; Springer: Dordrecht, The Netherlands, 2007.

15. Illies, J. Versuch einer allgemeinen biozönotischen Gliederung der Fließgewässer. Int. Rev. Gesamten Hydrobiol. Hydrogr. 1961, 46, 205-213. [CrossRef]

16. Schmidt-Kloiber, A.; Hering, D. www.freshwaterecology.info-An online tool that unifies, standardises and codifies more than 20,000 European freshwater organisms and their ecological preferences. Ecol. Indic. 2015, 53, 271-282. [CrossRef]

17. Pletterbauer, F.; Melcher, A.H.; Ferreira, T.; Schmutz, S. Impact of climate change on the structure of fish assemblages in European rivers. Hydrobiologia 2015, 744, 235-254.

18. Graham, C.T.; Harrod, C. Implications of climate change for the fishes of the British Isles. J. Fish Biol. 2009, 74, 1143-1205. [CrossRef] [PubMed]

19. Buisson, L.; Grenouillet, G. Contrasted impacts of climate change on stream fish assemblages along an environmental gradient. Divers. Distrib. 2009, 15, 613-626. [CrossRef]

20. Sandin, L.; Schmidt-Kloiber, A.; Svenning, J.; Jeppesen, E.; Friberg, N. A trait based approach to assess climate change sensitivity of freshwater invertebrates across Swedish ecoregions. Curr. Zool. 2014, 60, 221-232.

21. Domisch, S.; Araújo, M.B.; Bonada, N.; Pauls, S.U.; Jähnig, S.C.; Haase, P. Modelling distribution in European stream macroinvertebrates under future climates. Glob. Chang. Biol. 2013, 19, 752-762. [PubMed]

22. The Intergovernmental Panel on Climate Change (IPCC). Climate Change 2013: The Physical Science Basis; Stocker, T.F., Qin, D., Plattner, G.-K., Tignor, M., Allen, S.K., Boschung, J., Nauels, A., Xia, Y., Bex, V., Midgley, P.M., Eds.; Contribution of Working Group I to the Fifth Assessment Report of the Intergovernmental Panel on Climate Change; Cambridge University Press: Cambridge, UK; New York, NY, USA, 2013; p. 1535.

23. Haase, P.; Lohse, S.; Pauls, S.; Schindehütte, K.; Sundermann, A.; Rolauffs, P.; Hering, D. Assessing streams in Germany with benthic invertebrates: Development of a practical standardized protocol for macroinvertebrate sampling and sorting. Limnologica 2004, 34, 349-365.

24. Hering, D.; Schmidt-Kloiber, A.; Murphy, J.; Lücke, S.; Zamora-Muñoz, C.; López-Rodríguez, M.; Huber, T.; Graf, W. Potential impact of climate change on aquatic insects: A sensitivity analysis for European caddisflies (Trichoptera) based on distribution patterns and ecological preferences. Aquat. Sci. Res. Across Bound. 2009, 71, 3-14. [CrossRef]

25. Hering, D.; Borja, A.; Carvalho, L.; Feld, C.K. Assessment and recovery of European water bodies: Key messages from the WISER project. Hydrobiologia 2013, 704, 1-9. [CrossRef]

26. Arnholt, A.T. BSDA: Basic Statistics and Data Analysis R Package Version 1.01. 2012. Available online: https:/ / cran.r-project.org/web/packages/BSDA/index.html (accessed on 23 March 2012).

27. R Core Team. R: A Language and Environment for Statistical Computing; R Foundation of Statistical Computing: Vienna, Austria, 2015.

28. Wilby, R.L.; Orr, H.G.; Hedger, M.; Forrow, D.; Blackmore, M. Risks posed by climate change to the delivery of Water Framework Directive objectives in the UK. Environ. Int. 2006, 32, 1043-1055. [CrossRef] [PubMed] 
29. Schmutz, S.; Matulla, C.; Melcher, A.; Gerersdorfer, T.; Haas, P.; Formayer, H. Beurteilung der Auswirkungen Möglicher Klimaänderungen auf die Fischfauna Anhand Ausgewählter Fließgewässer. Endbericht, im Auftrag des BMLFUW, GZ 54 3895/163-V/4/03; Final Project Report; BMLFUW: Stubenring, Austria, 2004.

30. Daufresne, M.; Boet, P. Climate change impacts on structure and diversity of fish communities in rivers. Glob. Chang. Biol. 2007, 13, 2467-2478. [CrossRef]

31. Webb, B.; Walsh, A. Changing UK river temperatures and their impact on fish populations. In Hydrology: Science and Practice for the 21 st Century, Proceedings of the British Hydrological Society International Conference, Imperial College, London, UK, 12-16 July 2004; Webb, B., Acreman Maksimovic, C., Smithers, H., Kirby, C., Eds.; British Hydrological Society: Imperial College, London, UK, 2004; pp. 177-191.

32. United States Environmental Protectior Agency (USEPA). Implications of Climate Change for Bioassessment Programs and Approaches to Account for Effects; EPA/600/R-11/036A; Global Change Research Program, National Center for Environmental Assessment: Washington, DC, USA, 2012.

33. Hershkovitz, Y.; Dahm, V.; Lorenz, A.W.; Hering, D. A multi-trait approach for the identification and protection of European freshwater species that are potentially vulnerable to the impacts of climate change. Ecol. Indic. 2015, 50, 150-160. [CrossRef]

34. Logez, M.; Pont, D. Global warming and potential shift in reference conditions: The case of functional fish-based metrics. Hydrobiologia 2012, 704, 417-436. [CrossRef]

35. Scheffer, M.; Carpenter, S.; Foley, J.A.; Folke, C.; Walker, B. Catastrophic shifts in ecosystems. Nature 2001, 413, 591-596. [CrossRef] [PubMed]

36. Hering, D.; Carvalho, L.; Argillier, C.; Beklioglu, M.; Borja, A.; Cardoso, A.C.; Duel, H.; Ferreira, T.; Globevnik, L.; Hanganu, J.; et al. Managing aquatic ecosystems and water resources under multiple stress-An introduction to the MARS project. Sci. Total Environ. 2015, 503-504, 10-21. [CrossRef] [PubMed]

37. Kuemmerlen, M.; Schmalz, B.; Cai, Q.; Haase, P.; Fohrer, N.; Jähnig, S.C. An attack on two fronts: How predicted climate and land use changes affect the predicted distribution of stream macroinvertebrates. Freshw. Biol. 2015, 60, 1443-1458. [CrossRef]

38. Hamilton, A.T.; Barbour, M.T.; Bierwagen, B.G. Implications of global change for the maintenance of water quality and ecological integrity in the context of current water laws and environmental policies. Hydrobiologia 2010, 657, 263-278.

39. Bhowmik, A.K.; Schäfer, R.B. Large Scale Relationship between Aquatic Insect Traits and Climate. PLoS ONE 2015, 10, e0130025.

40. Lytle, D.A.; Poff, N.L. Adaptation to natural flow regimes. Trends Ecol. Evol. 2004, 19, 94-100. [CrossRef] [PubMed]

41. Poff, N.L.; Pyne, M.I.; Bledsoe, B.P.; Cuhaciyan, C.C.; Carlisle, D.M. Developing linkages between species traits and multiscaled environmental variation to explore vulnerability of stream benthic communities to climate change. J. N. Am. Benthol. Soc. 2010, 29, 1441-1458. [CrossRef]

42. Sundermann, A.; Stoll, S.; Haase, P. River restoration success depends on the species pool of the immediate surroundings. Ecol. Appl. 2011, 21, 1962-1971. [CrossRef] [PubMed]

43. Tonkin, J.D.; Stoll, S.; Sundermann, A.; Haase, P. Dispersal distance and the pool of taxa, but not barriers, determine the colonisation of restored river reaches by benthic invertebrates. Freshw. Biol. 2014, 59, 1843-1855. [CrossRef]

44. Früh, D.; Stoll, S.; Haase, P. Physico-chemical variables determining the invasion risk of freshwater habitats by alien mollusks and crustaceans. Ecol. Evol. 2012, 2, 2843-2853. [CrossRef] [PubMed]

45. Früh, D.; Stoll, S.; Haase, P. Physicochemical and morphological degradation of stream and river habitats increases invasion risk. Biol. Invasions 2012, 14, 2243-2253. [CrossRef]

46. Li, F.; Sundermann, A.; Stoll, S.; Haase, P. A newly developed dispersal metric indicates the succession of benthic invertebrates in restored rivers. Sci. Total Environ. 2016, 569-570, 1570-1578. [CrossRef] [PubMed]

47. Vaughan, I.P.; Ormerod, S.J. Large-scale, long-term trends in British river macroinvertebrates. Glob. Chang. Biol. 2012, 18, 2184-2194. [CrossRef]

48. Haase, P.; Li, F.; Sundermann, A.; Lorenz, A.; Tonkin, J.; Stoll, S. Three-dimensional range shifts in biodiversity driven by recent climate warming. PeerJ PrePrints 2015, 3, e1270.

49. Cañedo-Argüelles, M.; Boersma, K.S.; Bogan, M.T.; Olden, J.D.; Phillipsen, I.; Schriever, T.A.; Lytle, D.A. Dispersal strength determines meta-community structure in a dendritic riverine network. J. Biogeogr. 2015, 42, 778-790. [CrossRef] 
50. Tonkin, J.D.; Stoll, S.; Jähnig, S.C.; Haase, P. Contrasting metacommunity structure and beta diversity in a river-floodplain system. Oikos 2016, 125, 686-697. [CrossRef]

51. Isaak, D.J.; Young, M.K.; Luce, C.H.; Hostetler, S.W.; Wenger, S.J.; Peterson, E.E.; Ver Hoef, J.M.; Groce, M.C.; Horan, D.L.; Nagel, D.E. Slow climate velocities of mountain streams portend their role as refugia for cold-water biodiversity. Proc. Natl. Acad. Sci. USA 2016, 113, 4374-4379. [CrossRef] [PubMed]

52. Geismar, J.; Haase, P.; Nowak, C.; Sauer, J.; Pauls, S.U. Local population genetic structure of the montane caddisfly Drusus discolor is driven by overland dispersal and spatial scaling. Freshw. Biol. 2015, 60, $209-221$. [CrossRef]

53. Jaeger, K.L.; Olden, J.D.; Pelland, N.A. Climate change poised to threaten hydrologic connectivity and endemic fishes in dryland streams. Proc. Natl. Acad. Sci. USA 2014, 111, 13894-13899. [CrossRef] [PubMed]

54. Waters, J.M.; Craw, D.; Burridge, C.P.; Kennedy, M.; King, T.M.; Wallis, G.P. Within-river genetic connectivity patterns reflect contrasting geomorphology. J. Biogeogr. 2015, 42, 2452-2460. [CrossRef]

55. Altermatt, F.; Seymour, M.; Martinez, N. River network properties shape $\alpha$-diversity and community similarity patterns of aquatic insect communities across major drainage basins. J. Biogeogr. 2013, 40, 2249-2260. [CrossRef]

56. Heino, J. The importance of metacommunity ecology for environmental assessment research in the freshwater realm. Biol. Rev. 2013, 88, 166-178. [CrossRef] [PubMed]

57. Hering, D.; Borja, A.; Carstensen, J.; Carvalho, L.; Elliott, M.; Feld, C.K.; Heiskanen, A.-S.; Johnson, R.K.; Moe, J.; Pont, D.; et al. The European Water Framework Directive at the age of 10: A critical review of the achievements with recommendations for the future. Sci. Total Environ. 2010, 408, 4007-4019. [CrossRef] [PubMed]

58. Haase, P.; Frenzel, M.; Klotz, S.; Musche, M.; Stoll, S. The long-term ecological research (LTER) network: Relevance, current status, future perspective and examples from marine, freshwater and terrestrial long-term observation. Ecol. Indic. 2016, 65, 1-3. [CrossRef]

59. Halle, M.; Müller, A.; Sundermann, A. Temperature Preferences of Benthic Invertebrates as a Basis to Indicate Climate Change Effects in Rivers on the Biocenosis (in German: Ableitung von Temperaturpräferenzen des Makrozoobenthos für die Entwicklung eines Verfahrens zur Indikation Biozönotischer Wirkungen des Klimawandels in Fließgewässern); KLIWA-Berichte Heft 20; LUBW Landesanstalt für Umwelt, Messungen und Naturschutz Baden-Württemberg: Karlsruhe, Germany, 2016. 